\title{
Method for the earlier recognition of abnormal stature
}

\author{
A AYNSLEY GREEN AND J A MACFARLANE \\ University Department of Paediatrics, John Radcliffe Hospital, and Department of Community Health, \\ Radcliffe Infirmary, Oxford
}

SUMmaRY Two hundred and twenty seven children with a height below the 3rd or above the 97th centile were seen consecutively in the Oxford growth clinic. Their referral ages were analysed to determine the pattern of referral. Eighty seven per cent of the children had short stature. In $40 \%$ of these there was an organic reason for abnormal growth-the most common conditions being growth hormone deficiency, hypothyroidism, and Turner's syndrome-but the rest had genetic short stature or 'constitutional' delay in puberty. Many children who could have been treated effectively were referred too late, for effective treatment to ensure normal adult height because of this we have developed full sized percentile charts to screen populations of children so that abnormal stature can be recognised immediately.

The treatment of children with abnormal growth is preceded by 2 distinct stages of management. The first is the identification of such children in the community and the second is appropriate investigation-usually in hospital as an outpatient or inpatient. The latter stage, although now well defined, is totally dependent on the former, but unfortunately referral of potentially treatable cases is usually late.

Tanner in $1975^{1}$ and Vimpani et al. ${ }^{2}$ in 1977 reported that many children with growth hormone deficiency in the United Kingdom were being referred for investigation at an unacceptably advanced age. This is particularly serious in the case of growth hormone (GH) deficiency since delay after the age of 7-8 years means that even with treatment a final height in the normal adult range is unlikely. ${ }^{1}$ Tanner made a plea for earlier diagnosis but despite this the mean age of referral was still 8.1 years in the report of the Medical Research Council's working party on growth hormone deficiency in $1979,{ }^{3}$ and in 1981 only $42 \%$ of growth hormone deficient children started treatment under the age of 10 years (E C Burns, 1981, personal communication). Growth hormone deficiency is, however, only one condition causing growth retardation where early treatment is essential. Similar considerations apply to the treatment of excessive growth and tall stature in childhood.

In view of the importance of early detection we analysed the referral ages of 227 consecutive children attending the Oxford growth clinic to assess the pattern of age of referral for all causes of abnormal stature. We also give details of 2 full sized growth charts specifically designed to improve early referral.

\section{Patients}

Data from 227 consecutive patients with a height $<3$ rd centile or $>97$ th centile referred to the Oxford growth clinic for assessment were analysed according to the aetiology of the growth disturbance. The mean and modal ages of referral for each diagnostic group were calculated.

\section{Results}

Details of the patients are shown in Table 1. Most children were referred because of short stature and there were more boys than girls in this group. Of referrals for short stature $45 \%$ were for children with genetic short stature, $15 \%$ were children with 'constitutional' delay of puberty, and $60 \%$ were essentially normal. The mean age of referral of children with genetic short stature was 12 years (Table 2), the mode was between 13 and 14 years, and $36 \%$ of children in this category were referred after the age of 12 years when many were experiencing psychological difficulties related to their size and uncertainty of their final height.

Table 1 Analysis of 227 referrals to Oxford growth clinic

\begin{tabular}{lccc}
\hline & Total (\%) & Boys & Girls \\
\hline Short stature ( $<$ 3rd centile) & $198(87)$ & 126 & 72 \\
Tall stature ( $>97$ th centile) & $29(13)$ & 13 & 16 \\
\hline Total & 227 & 139 & 88 \\
\hline
\end{tabular}


Table 2 Analysis of causes of short stature and age at referral

\begin{tabular}{lrrrr}
\hline & No & $\%$ & $\begin{array}{l}\text { Mean age at } \\
\text { referral (years) }\end{array}$ & $\begin{array}{r}\text { Range } \\
(\text { years })\end{array}$ \\
\hline $\begin{array}{lrrr}\text { Normal } \\
\text { Short normal }\end{array}$ & 89 & 45 & 12 & $2-17$ \\
Short delay & 30 & 15 & 15 & $12-20$ \\
Total & 119 & 60 & & \\
Abnormal & & & & $3-14$ \\
Hypothyroidism & 18 & 9 & 9 & $3-16$ \\
Turner's Syndrome & 15 & 7 & 12 & $2-16$ \\
$\begin{array}{l}\text { GH deficiency } \\
\text { Other causes }\end{array}$ & 11 & 6 & 7 & \\
Total & 35 & 18 & 11 & \\
\hline
\end{tabular}

In $40 \%$ of the short children there was an organic reason for growth retardation and over half of these fell into 3 main categories (Table 2). The mean age of referral for 'idiopathic' growth hormone deficiency was 7 years, but 1 patient was aged 11 years. The mean age of referral of girls with Turner's syndrome was 12 years, but the mode was 16 years. Hypothyroidism affected children in a wide age band at referral.

In $18 \%$ of short children some other organic cause for growth retardation was evident. The mean age of referral for this mixed group was 11 years and many had a clear long standing history of slow growth. A wide variety of conditions was diagnosed in this group, the most common being coeliac disease, psychosocial deprivation, Russell Silver syndrome, and dysmorphic short stature. Pseudohypoparathyroidism and hypogonadism were also found.

More girls (16) than boys (13) were referred because of tall stature. Their ages ranged from 3-18 years and both the mean age and mode were 13 years. Some girls had pathological conditions, including Marfan's syndrome, unrecognised congenital adrenal hyperplasia, and thyrotoxicosis. All the boys, except 3 with the XYY syndrome, had 'constitutional' tall stature: 1 boy with a history of at least 7 years' excessive growth was not referred until he was 17 years when his height was $210 \mathrm{~cm}$ (82 inches). Three other boys were treated with a combined medical and surgical approach-high dose testosterone and femoral and tibial epiphysiodesis.

\section{Discussion}

Where there is a treatable cause of abnormal stature in childhood it is important to recognise and treat this as early as possible to protect the final adult height potential. If the problem is untreatable then it is also important for the child and his or her family to discuss the implications of the diagnosis at the earliest opportunity to minimise the profound psychological disturbances that can affect patients and their families.
Why then, in an area such as Oxford, that has a good social class distribution, an excellent primary health care service, and easy access to hospital facilities, is referral of children with growth abnormalities still so late? The mean age of referral of children with growth hormone deficiency is only marginally earlier than the national average, and the modal age of referral of girls with Turner's syndrome means that these girls have fallen considerably behind their peers not only in growth but also in sexual development.

We believe that this delay is caused mainly by a failure of primary health care services to identify children with growth disorders. Lack of parental awareness of their child's abnormal growth

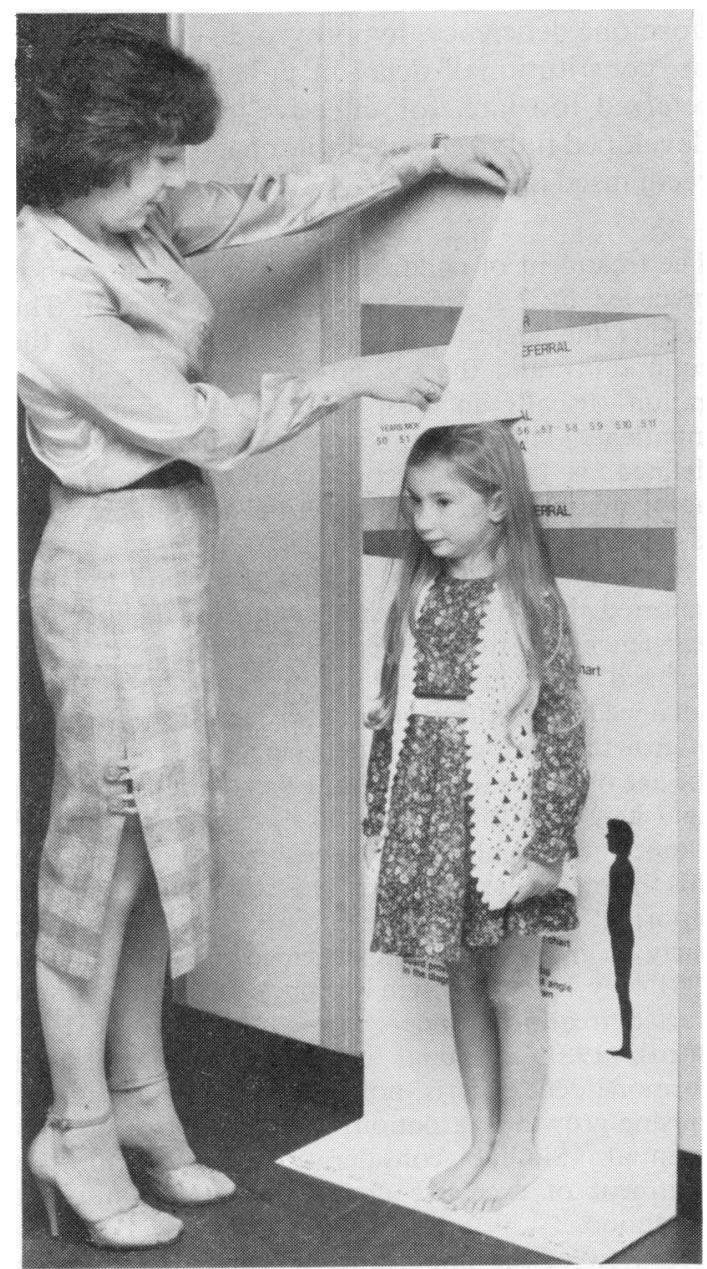

Fig. 1 Growth chart for children aged 4 years 11 months to 6 years (printed on laminated board which folds in 2 places to make it portable). 


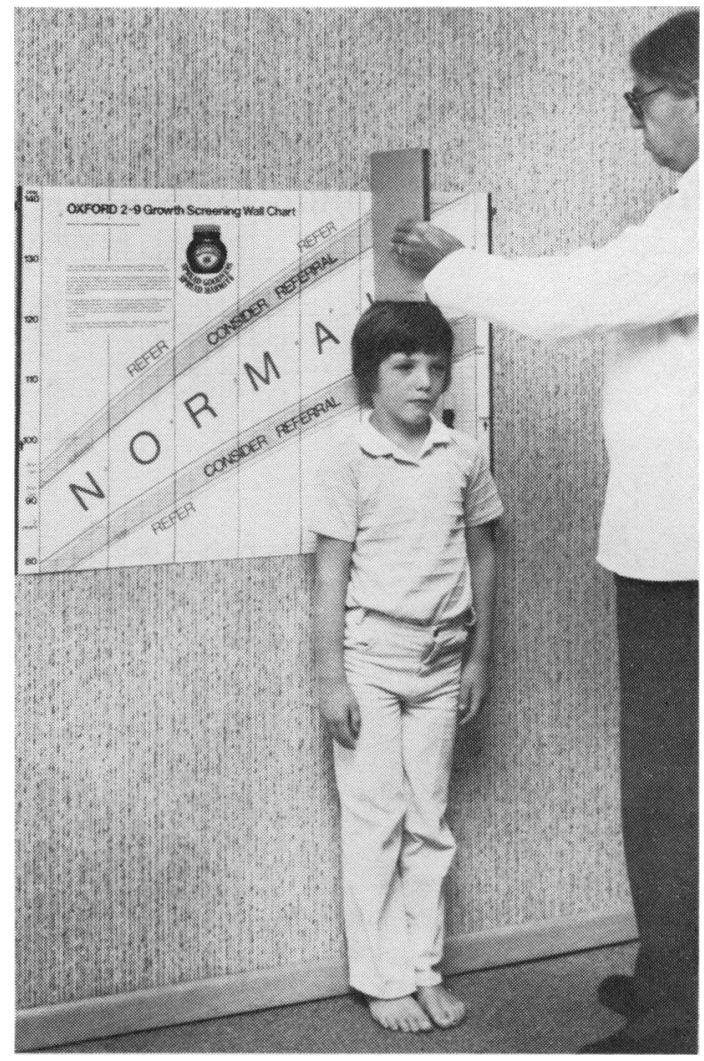

Fig. 2 Growth chart for children aged 2 years to 9 years (printed on laminated paper and fixed to a wall or door at a specified height from the floor).

was usually denied. The reasons for this failure include:

(1) No appropriate measuring equipment in many surgeries and child health clinics.

(2) Limited availability of appropriate percentile charts, associated in some cases with a lack of understanding of their use.

(3) No routine height measurement during medical examinations at school entry.

(4) Lack of awareness by family practitioners of recent advances in the treatment of abnormal growth.

\section{The Oxford growth screening charts}

Because the first 2 of these problems could be overcome by using a simple and cheap device to screen large populations of children we have, in collaboration with $\mathrm{Mr} \mathbf{R}$ Whitehouse and Castlemead Publications, devised 2 full sized percentile charts (Figs. 1 and 2). The first of these charts (Fig. 1) is for children aged between 4 years 11 months and 6 years, is portable, and is designed to be used by school nurses or school doctors to screen children for abnormal stature at the school entry medical examinations. The second is a wall chart (Fig. 2) for age 2 to 9 years and is designed for use by health visitors, clinical medical officers, and general practitioners in health clinics and family practitioner surgeries. The child stands against the wall with its head centred against the appropriate age mark on the chart and from the position of the head against the percentile lines (Figs. 1 and 2) it can be seen immediately whether the child's height falls within the normal percentile range. Where a height falls, between the 3rd percentile and the -3 SD limit or between the 97 th percentile and the +3 SD limit the child should be considered for referral for further study and this consideration should include the mid-parental height correction, using the appropriate Tanner and Whitehouse chart. A height below the -3 SD or above the +3 SD limit should mean immediate referral to a growth specialist for further investigation.

Ideally each child's height should be recorded accurately on an individual conventional growth chart which would be kept in the case records so that sequential heights may be added over a period of time to obtain a record of longitudinal growth. While this council of perfection may prevail in a few areas we know that it rarely does so in Oxfordshire and is even less likely to prevail in areas of social deprivation. The use of these wall charts should lead to earlier identification of abnormal stature, but this method will only identify children whose stature has fallen outside the normal limits and not those with abnormal growth whose heights are still in the normal range. The use of these charts is being evaluated in a field study in Oxfordshire schools.

We thank the Department of Medical Illustration, John Radcliffe Hospital; Mr Reg Whitehouse for providing the most recent growth data; Messrs Castlemead, Ware, Hertford for manufacturing the charts; and the Child Growth Foundation for support.

\section{References}

1 Tanner JM. Towards complete success in the treatment of growth hormone deficiency: a plea for earlier ascertainment. Health Trends 1975; 7: 61-5.

2 Vimpani GV, Vimpani AF, Farquhar JW. Failure to refer children of short stature for specialist opinion: a Scottish survey (abstract). Arch Dis Child 1977; 52: 981.

3 Milner RDG, Russell-Fraser T, Brook CGD, et al. Experience with human growth hormone in Great Britain; the report of the MRC Working Party. Clin Endocrinol $(O x f) 1979 ; 11$ : 15-38.

Correspondence to Dr J A Macfarlane, Community Health Offices, The Radcliffe Infirmary, Oxford OX2 6HE.

Received 18 March 1983 